\title{
Chromogenic in situ hybridization is a reliable assay for detection of $A L K$ rearrangements in adenocarcinomas of the lung
}

\author{
Hans-Ulrich Schildhaus ${ }^{1,4}$, Karl-Friedrich Deml ${ }^{1,4}$, Katja Schmitz ${ }^{1,2}$, Maren Meiboom ${ }^{3}$, \\ Elke Binot ${ }^{1}$, Sven Hauke ${ }^{3}$, Sabine Merkelbach-Bruse ${ }^{1}$ and Reinhard Büttner ${ }^{1}$ \\ ${ }^{1}$ Institute of Pathology, University Hospital Cologne (as part of the Lung Cancer Group Cologne (LCGC)), \\ Cologne, Germany; ${ }^{2}$ Institute of Pathology, University Hospital Göttingen, Göttingen, Germany and \\ ${ }^{3}$ ZytoVision GmbH, Bremerhaven, Germany
}

\begin{abstract}
Reliable detection of anaplastic lymphoma kinase $(A L K)$ rearrangements is a prerequisite for personalized treatment of lung cancer patients, as $A L K$ rearrangements represent a predictive biomarker for the therapy with specific tyrosine kinase inhibitors. Currently, fluorescent in situ hybridization (FISH) is considered to be the standard method for assessing formalin-fixed and paraffin-embedded tissue for $A L K$ inversions and translocations. However, FISH requires a specialized equipment, the signals fade rapidly and it is difficult to detect overall morphology and tumor heterogeneity. Chromogenic in situ hybridization (CISH) has been successfully introduced as an alternative test for the detection of several genetic aberrations. This study validates a newly developed $A L K$ CISH assay by comparing FISH and $\mathrm{CISH}$ signal patterns in lung cancer samples with and without $A L K$ rearrangements. One hundred adenocarcinomas of the lung were included in this study, among them 17 with known $A L K$ rearrangement. FISH and CISH were carried out and evaluated according to the manufacturers' recommendations. For both assays, tumors were considered positive if $\geq 15 \%$ of tumor cells showed either isolated $3^{\prime}$ signals or break-apart patterns or a combination of both. A subset of tumors was exemplarily examined by using a novel EML4 (echinoderm microtubule-associated protein-like 4) $\mathrm{CISH}$ probe. Red, green and fusion $\mathrm{CISH}$ signals were clearcut and different signal patterns were easily recognized. The percentage of aberrant tumor cells was statistically highly correlated $(P<0.001)$ between FISH and $\mathrm{CISH}$. On the basis of 86 samples that were evaluable by $A L K \mathrm{CISH}$, we found a $100 \%$ sensitivity and $100 \%$ specificity of this assay. Furthermore, EML4 rearrangements could be recognized by CISH. CISH is a highly reliable, sensitive and specific method for the detection of $A L K$ gene rearrangements in pulmonary adenocarcinomas. Our results suggest that $\mathrm{CISH}$ might serve as a suitable alternative to FISH, which is the current gold standard.
\end{abstract}

Modern Pathology (2013) 26, 1468-1477; doi:10.1038/modpathol.2013.95; published online 7 June 2013

Keywords: $A L K$ rearrangement; chromogenic in situ hybridization; EML4-ALK; fluorescent in situ hybridization; lung cancer

Over the past few years, detection of $A L K$ (anaplastic lymphoma kinase) gene rearrangements became highly relevant for the molecular diagnosis of lung cancer. It was shown that the EML4-ALK fusion protein, occurring in $2-7 \%$ of pulmonary adenocarcinomas, ${ }^{1}$ has transforming oncogenic

Correspondence: Dr H-U Schildhaus, MD, Institute of Pathology, University Hospital Cologne (as part of the Lung Cancer Group Cologne (LCGC)), Kerpener Strasse 62, Cologne, Köln 50937, Germany.

E-mail: hans-ulrich.schildhaus@uk-koeln.de

${ }^{4}$ The first two authors contributed equally to this work.

Received 5 February 2013; revised and accepted 22 April 2013; published online 7 June 2013 activity, making it a driver mutation in these tumors. The involvement of a tyrosine kinase in this fusion, however, represents a potential therapeutic target. ${ }^{2,3}$ Meanwhile, the ALK inhibitor crizotinib was approved by the US Food and Drug Administration (FDA) and the European Medicines Agency (EMA) for the treatment of patients with locally advanced or metastatic $A L K$-positive/rearranged lung cancer. Thus, $A L K$ rearrangements define a novel molecular subtype of lung cancer. Therefore, there is an urgent need for methods that can reliably and easily detect $A L K$ rearrangements in the daily routine diagnostics of lung cancer specimens.

The $A L K$ gene, located on chromosome $2 \mathrm{p} 23$, was initially identified as the fusion partner of the 
nucleophosmin gene (NPM1) in anaplastic large-cell lymphomas. ${ }^{4}$ This fusion gene resulting from a $\mathrm{t}(2 ; 5)(\mathrm{p} 23 ; \mathrm{q} 35)$ translocation encodes a chimeric protein consisting of the N-terminal oligomerization motif of NPM1, followed by the entire cytoplasmic region of ALK containing the tyrosine kinase domain. The oncogenic NPM1-ALK fusion protein is constitutively activated through autophosphorylation and mediates malignant cell transformation by activating downstream effectors. Owing to the fusion, ALK dimerization is independent of binding ALK ligands, for example, growth factors pleiotrophin and midkine..$^{5,6}$

The molecular mechanism of ALK activation is characterized by a chromosomal rearrangement and the formation of a chimeric protein, which lacks the regulatory $\mathrm{N}$-terminal extracellular ligand binding domain of ALK and which consists of two functionally relevant motifs: (i) a domain that enables homodimerization without ligand binding and (ii) the C-terminal kinase domain of ALK. Besides NPM1-ALK, this mechanism was also found in other tumors and in various types of $A L K$ rearrangements. In this way, ALK is turned oncogenic by fusion of its tyrosine kinase domain to N-terminal motifs of TPM3 or TPM4 in anaplastic large-cell lymphoma and inflammatory myofibroblastic tumors ${ }^{7,8}$ or VCL in renal medullary carcinoma. ${ }^{9}$ In a subset of lung cancer $A L K$ is rearranged by a translocation to KIF5B, ${ }^{10} \mathrm{TFG}^{11}$ or most often by an intrachromosomal inversion, resulting in a fusion gene with EML4 (echinoderm microtubule-associated protein-like 4). ${ }^{2}$ Constitutive activation of the ALK tyrosine kinase domain due to homodimerization driven by oligomerization domains of ALK fusion partners appears again to be the general underlying mechanism of oncogenic transformation in lung cancer regardless of the fusion partners. ${ }^{12}$

In pulmonary carcinomas, the EML4-ALK inversion inv(2)(p21;p23) is predominantly associated with adenocarcinoma histology and was thought to mutually exclude EGFR gene mutations; thus, representing a unique molecular subtype. As already mentioned, $A L K$ rearrangement is highly predictive for therapies with specific ALK inhibitors, whereas patients with $A L K$-rearranged tumors do not respond to EGFR TKI and conventional chemotherapy. Therefore, recent NCCN and ESMO guidelines recommended to test metastatic or locally advanced non-small-cell lung cancer patients routinely for $A L K$ rearrangements. ${ }^{13,14}$

Currently, fluorescent in situ hybridization (FISH), sensitive immunohistochemistry (IHC) and reverse transcriptase-polymerase chain reaction (RT-PCR) are used to assess formalin-fixed, paraffin-embedded tissue for $A L K$ rearrangements. ${ }^{15-17}$ FISH requires a specialized and expensive equipment, the signals fade rapidly and it is difficult to detect overall morphology and tumor heterogeneity. ${ }^{18} \quad A L K \quad$ IHC studies showed inhomogeneous results varying from low to high sensitivity. ${ }^{10,15,16,19,20}$ For RT-PCR, RNA of good quality and a multiplex system is required owing to the high variability of $A L K$ rearrangements; therefore, several clinical studies used FISH as the method of choice. ${ }^{1,21}$

Hence, other methods with accuracy comparable to FISH but without its disadvantages are desirable. For the diagnosis of HER2 status in breast cancers, rearranged $S S 18$ in synovial sarcoma and the detection of EGFR amplification in lung carcinomas CISH (chromogenic in situ hybridization) has been shown to be highly comparable with FISH in terms of sensitivity and specificity. ${ }^{22-24}$ However, the detection of other genomic rearrangements, such as inversions or complex translocations, has not yet been studied extensively with CISH. This is because of the fact that fusion signals and isolated signals are often only hardly distinguishable by CISH if conventional chromogenic substrates are used. Recently, a very limited number of publications has shown the potential applicability of bright field in situ hybridization assays (BrISH; ie, silver in situ hybridization or CISH) for the detection of $A L K$ rearrangements in tumor samples. ${ }^{25,26}$

In our study, we have established and validated a newly developed commercially available dual-color $A L K$ break-apart CISH assay on a series of clinical lung cancer samples. Results are compared with those obtained by an FDA-approved $A L K$ FISH assay to show the feasibility, sensitivity and specificity of this CISH test, which uses unique red and green chromophores to produce highly contrasting and thus easily distinguishable signals.

\section{Materials and methods}

One hundred cases of formalin-fixed, paraffinembedded lung adenocarcinomas with known $A L K$ status detected by FISH were selected from the files of the Institute of Pathology at the University Hospital Cologne. Seventeen of those cases had a positive $A L K$ status and 83 were $A L K$ negative. Sixty-two of 100 specimens were biopsies, thereof 11 metastases. Thirty-eight of the specimens were surgical resections. All diagnoses were reviewed by two experienced pathologists and confirmed by immunostainings if appropriate and/or necessary. Diagnoses and grading of tumors were made in accordance with the current WHO classification system and the IASLC classification. ${ }^{27,28}$ In all cases, the same tissue block was used for FISH and CISH assays.

\section{ALK FISH}

FISH was carried out by using $4-\mu$ m-thick sections. Slides were pretreated by using the VP2000 processor (Abbott Molecular, Wiesbaden, Germany). The Abbott/Vysis LSI ALK Dual Color Break-Apart Rearrangement Probe (Abbott) was diluted in Vysis 
LSI/WCP Hybridization Buffer (Abbott) and denatured on the tissue slides at $85^{\circ} \mathrm{C}$ for $10 \mathrm{~min}$. Denaturation and hybridization (at $37^{\circ} \mathrm{C}$ overnight) were carried out by using a ThermoBrite hybridization oven (Abbott). After hybridization, washes $\left(2 \times\right.$ SSC, $0.3 \%$ NP40) were conducted at $72{ }^{\circ} \mathrm{C}$ for 2 min. Slides were counterstained with DAPI and coverslipped. A Leica DM5500 fluorescence microscope with $\times 63$ and $\times 100$ objectives and appropriate filter sets were used for evaluation by two investigators (HUS and KS).

The evaluation criteria provided by the manufacturer were applied. In brief, cells were considered positive if a break-apart pattern of orange and green signals or at least one additional orange signal or a combination of both patterns appeared. Tumors were considered to reveal an $A L K$ rearrangement if at least $15 \%$ of cells were positive.

\section{$A L K$ and EML4 Break-Apart Dual-Color CISH}

$A L K$ gene status was determined by using the ZytoDot 2C SPEC ALK break-apart probe (ZytoVision, Bremerhaven, Germany). The probe is composed of digoxigenin (dig)-labeled polynucleotide probes hybridizing proximal and dinitrophenyl (DNP)labeled polynucleotide probes hybridizing distal to the $A L K$ gene breakpoint region. Tissue pretreatment and probe detection were performed by using the ZytoDot ${ }^{\circledR} 2 \mathrm{C}^{\mathrm{TM}}$ CISH Implementation Kit (ZytoVision) according to the manufacturer's instructions. The dig-labeled probes were detected by horseradish peroxidase (HRP) and represented as a green signal, the DNP-labeled polynucleotide probes were detected with an alkaline phosphatase (AP) resulting in red signals.

Briefly, after deparaffinization in xylene and ethanol, the slides were incubated in $3 \%$ hydrogen peroxide in methanol for $5 \mathrm{~min}$ to quench endogenous peroxidase activity. Fifteen-minute incubation in EDTA pretreatment buffer (ZytoVision) at $\geq 95^{\circ} \mathrm{C}$ in a water bath, followed by digestion with pepsin solution (ZytoVision) at RT for 6 min was used for de-masking the tissues. The sections were dehydrated in graded ethanol and air-dried. A 10-20 $\mu$ l of probe were applied to the tissue, covered with a coverslip, sealed with rubber cement and codenaturated with the tissue on a hot plate at $79^{\circ} \mathrm{C}$ for $5 \mathrm{~min}$. The slides were immediately transferred into a humidity chamber and hybridized overnight at $37^{\circ} \mathrm{C}$ in a heating cabinet/hybridization oven. After removal of the coverslips, the slides were washed for $5 \mathrm{~min}$ in Wash Buffer SSC (ZytoVision) at $80^{\circ} \mathrm{C}$ and in water for $2 \mathrm{~min}$ at room temperature. Probe detection was performed with sequential incubation of combined mouse-anti-dig/rabbit-anti-DNP and combined anti-mouse-HRP/anti-rabbit-AP antibody mixtures, each for $15 \mathrm{~min}$ at $37^{\circ} \mathrm{C}$, followed by incubation with the color substrates AP-Red for $10 \mathrm{~min}$ at room temperature and HRP-Green for
10 min at room temperature (ZytoVision). The tissue was counterstained with the Nuclear Blue Solution provided by the kit, washed in running tap water for 2 min and dehydrated in a short sequence of $100 \%$ ethanol $(3 \times 30 \mathrm{~s})$ and xylene $(2 \times 30 \mathrm{~s})$ before cover slipping.

Slides were evaluated by light microscopy (Leica DM2500) under a $\times 100$ objective lens. One hundred non-overlapping cells were evaluated by two investigators (HUS and MM) blinded to the FISH results. As we attempted to use the same tissue block for FISH and CISH, we were able to count only $<100$ tumor cell in 16 cases because there was only little tumor left. Two signal patterns were accounted as rearrangements of the $A L K$ locus: (a) break-apart pattern: a red/green signal pair together with a separate red and a separate green signal representing the intact and the rearranged $A L K$ locus, respectively. Red and green signals were counted as separate if the distance between the signals was at least the size of one signal diameter. (b) Isolated 3'-signal pattern: a red/green signal pair together with one or multiple isolated red signals representing the intact $A L K$ locus and the rearranged $A L K$ locus with loss of the region proximal to the $A L K$ breakpoint, respectively. The occurrence of multiple isolated $3^{\prime}$ signals is thought to indicate gains of the rearranged allele. Cases were considered positive for $A L K$ rearrangement if one or both of these patterns were detected in $\geq 15 \%$ of the tumor cells.

In addition, three tumors were exemplarily examined with a novel EML4 CISH assay (ZytoDot 2C SPEC EML4 break-apart probe; ZytoVision) using the same hybridization protocol and evaluation criteria.

\section{Mutational Analyses (KRAS, EGFR)}

For DNA isolation from FFPE tissue, a tumor area was macrodissected for subsequent DNA isolation. DNA purification was performed using the BioRobot M48 Robotic Workstation and the corresponding MagAttract DNA Mini M48 Kit (Qiagen) following the manufacturer's instructions.

For the detection of KRAS mutations in exon 2 (codons 12 and 13) and exon 3 (codons 59, 61 and 63), high-resolution melting analysis (HRM) analyses were performed as described previously. ${ }^{29}$ Primers (HPLC purified; Sigma Aldrich, Munich, Germany) were designed with the LightCycler Probe Design 2.0 software (Roche Diagnostics) and checked for specificity by using the basic local alignment software tool (BLAST) from the National Center for Biotechnology Information (NCBI) (http://blast.ncbi.nlm.nih.gov/Blast.cgi).

Sanger sequencing was used for verification and identification of KRAS mutation types from PCR fragments generated during HRM analysis and for detection of EGFR mutations in exons 18, 19 and 21. 
A complete compilation of the applied technical procedures for analyzing EGFR mutations of all institutes from the German Panel for Mutation Analyses in NSCLC, including DNA extraction methods, primer sequences and PCR conditions, is available online (www.dgp-berlin.de/downloads/public/ protocols/EGFR_Mutations_Protocols_engl.pdf). All sequencing reactions were performed in duplicate.

\section{Statistics}

For statistical analyses, we used SPSS 20 software (IBM, Armonk, NY, USA). Spearman's $\rho$ and $t$-tests were used if appropriate. All tests were two-sided, with a $95 \%$ confidence interval.

\section{Results}

\section{Study Group}

We examined 100 adenocarcinomas of the lung by FISH and CISH. The mean age of the 17 patients with positive $A L K$ status was 49 years (Table 1), whereas patients with $A L K$-negative tumors were significantly older (mean age: 65 years; $t$-test, $P<0.001)$. The $A L K$-positive group consisted of 10 females and 7 males. None of the $A L K$-rearranged tumors harbored KRAS or EGFR mutations. However, we found 3/62 (4.8\%) EGFR and 26/81 $(32.1 \%) \quad K R A S$ mutations in the $A L K$-negative cohort.

\section{Feasibility of CISH}

CISH assays were conducted only once and were not repeated with adapted digestion protocols as we

Table $1 A L K$-positive pulmonary adenocarcinomas

\begin{tabular}{lccccc}
\hline Case & Age/ & $\begin{array}{c}\text { ALK CISH } \\
\text { (percentage } \\
\text { of positive } \\
\text { tumor cells) }\end{array}$ & $\begin{array}{c}\text { ALK FISH } \\
\text { (percentage } \\
\text { of positive } \\
\text { tumor cells) }\end{array}$ & KRAS & EGFR \\
\hline 1 & $30 / \mathrm{m}$ & 21 & 27 & $\mathrm{Wt}$ & $\mathrm{Wt}$ \\
2 & $50 / \mathrm{f}$ & 54 & 70 & $\mathrm{Wt}$ & $\mathrm{Wt}$ \\
3 & $63 / \mathrm{f}$ & 33 & 27 & $\mathrm{ND}$ & $\mathrm{ND}$ \\
4 & $42 / \mathrm{m}$ & 64 & 60 & $\mathrm{Wt}$ & $\mathrm{ND}$ \\
5 & $28 / \mathrm{f}$ & 36 & 36 & $\mathrm{ND}$ & $\mathrm{ND}$ \\
6 & $54 / \mathrm{m}$ & 16 & 23 & $\mathrm{Wt}$ & $\mathrm{Wt}$ \\
7 & $57 / \mathrm{f}$ & 29 & 43 & $\mathrm{Wt}$ & $\mathrm{Wt}$ \\
8 & $65 / \mathrm{m}$ & 20 & 25 & $\mathrm{Wt}$ & $\mathrm{Wt}$ \\
9 & $51 / \mathrm{m}$ & 50 & 40 & $\mathrm{ND}$ & $\mathrm{ND}$ \\
10 & $48 / \mathrm{f}$ & 62 & 60 & $\mathrm{Wt}$ & $\mathrm{Wt}$ \\
11 & $42 / \mathrm{f}$ & 36 & 35 & $\mathrm{Wt}$ & $\mathrm{Wt}$ \\
12 & $52 / \mathrm{f}$ & 80 & 70 & $\mathrm{Wt}$ & $\mathrm{Wt}$ \\
13 & $49 / \mathrm{f}$ & 75 & 69 & $\mathrm{Wt}$ & $\mathrm{Wt}$ \\
14 & $35 / \mathrm{m}$ & 90 & 98 & $\mathrm{Wt}$ & $\mathrm{Wt}$ \\
15 & $39 / \mathrm{f}$ & 77 & 85 & $\mathrm{Wt}$ & $\mathrm{Wt}$ \\
16 & $42 / \mathrm{f}$ & 49 & 24 & $\mathrm{Wt}$ & $\mathrm{Wt}$ \\
17 & $83 / \mathrm{m}$ & $\mathrm{n} . \mathrm{d}$. & 100 & $\mathrm{ND}$ & $\mathrm{ND}$ \\
\hline
\end{tabular}

m, male; f, female; wt, wild type; ND, not determined. aimed to investigate the performance quality of the assay according to the standard protocol. CISH results could be obtained from 86 tumor samples, whereas 14 cases were not evaluable for several reasons. In two cases, too little tumor tissue was left on the CISH slides. Twelve further cases were not assessable by CISH because of technical causes. Those included missing signals (9 cases, among them 1 sample, which was neither interpretable by FISH nor CISH because of bad tissue preservation), overdigestion $(n=1)$ and washed off tumor tissue ( $n=2$, among them one $A L K$-rearranged tumor). Seven out of the total of $14 \mathrm{CISH}$ slides that were not interpretable were surgical samples and seven were biopsies. This results in a CISH detection rate of $88 \%$ (86 out of 98 samples with sufficient tumor tissue). In terms of handling time of the assay, a 2-day protocol is applied for CISH, as it is for FISH. The reading time for CISH and FISH assays was nearly the same.

CISH assays were easily interpretable after a short training period. The discrimination between dark red and dark green signals was clearcut in the vast majority of tumor cells (Figure 1). However, it turned out to be important to use a $\times 100$ objective with oil immersion and to use maximum brightness of the microscope. Overall red and green signals were well balanced, and none of the tumor was interpretable because of bad red/green discrimination. The wellpreserved architecture of the tissue and characteristics of the cytoplasm facilitated the distinction between neoplastic and non-neoplastic tissue.

\section{Correlation Between FISH and CISH}

CISH assays were evaluated blinded to the FISH results. For each sample, the percentage of tumor cells with aberrant signal patterns was determined as described in the Materials and Methods section. CISH results were then compared with those previously obtained from the same tumor blocks by applying the FDA-approved Abbott FISH assay.

Sixteen out of the $17 A L K$-rearranged tumors were identified by CISH (Table 1), whereas no falsepositive sample occurred (Figure 2). One case was missed by CISH because the tumor tissue was washed off. Therefore, all evaluable CISH assays showed a $100 \%$ concordance with FISH for $A L K$-negative as well as for $A L K$-positive cases. As a major finding of our work, these results indicate $100 \%$ sensitivity and $100 \%$ specificity of the CISH assay in terms of correct classification as $A L K$ positive or negative.

Furthermore, we noticed a statistically highly significant correlation between both assays concerning the percentages of aberrant tumor cells in the whole cohort (Spearman's $\rho$ test, $P<0.001$; Figure 2). In the $A L K$-positive subgroup, rearrangement signals were identified in 23-98\% (mean: $49.5 \pm$ $23.9 \%$ ) of tumor cells by FISH and in $16-90 \%$ (mean: $49.5 \pm 23.4 \%$ ) by CISH. 
Ten out of $83 A L K$-negative cases showed slightly increased percentages (7-14\%) of tumor cells with aberrant signal patterns in either FISH or CISH (Table 2) representing a subgroup of diagnostically difficult cases. Seven out of 99 cases $(7 \%)$ fell into this category by FISH, but only 3 out of 86 CISH assays $(3.5 \%)$ revealed such a borderline negative result. In this subgroup, the mean percentage of positive tumor cells was 9.1 for FISH and 9.0 for CISH. Notably, two of these cases were KRAS mutated but no EGFR mutation was found (Table 2).

\section{CISH Signal Patterns}

We found a great variety of signal patterns in both $A L K$-positive and -negative lesions. In normal non-neoplastic nuclei, one or two fusion signals were seen, which consist of a dark red and a dark green signal in close proximity. The red probe flanks the $A L K$ gene distally (ie, in the direction of the telomere of the short arm of chromosome 2) and is closely located to the $3^{\prime}$ end of the gene, which includes exon 20 and the tyrosine kinase domain. The green probe is located in the $A L K$ gene proximally to the most frequent break point in intron 19. In non-neoplastic and tumor tissue, we observed that fusion signals appear dark brownish or less frequently in the form of overlapping red and green signals.

Among $A L K$-negative tumors, we only rarely found cases with one or two fusion signals (Figure 1b), which appeared quite similar to non-neoplastic tissue in terms of signal patterns. These tumors exhibited almost exclusively dark brownish fusion signals, but only few (if any) isolated red or green signals. The majority of $A L K$-negative tumors, however, were characterized by slight to high polysomy (Figure 1d) with multiple fusion signals. As these polysomic tumors have very

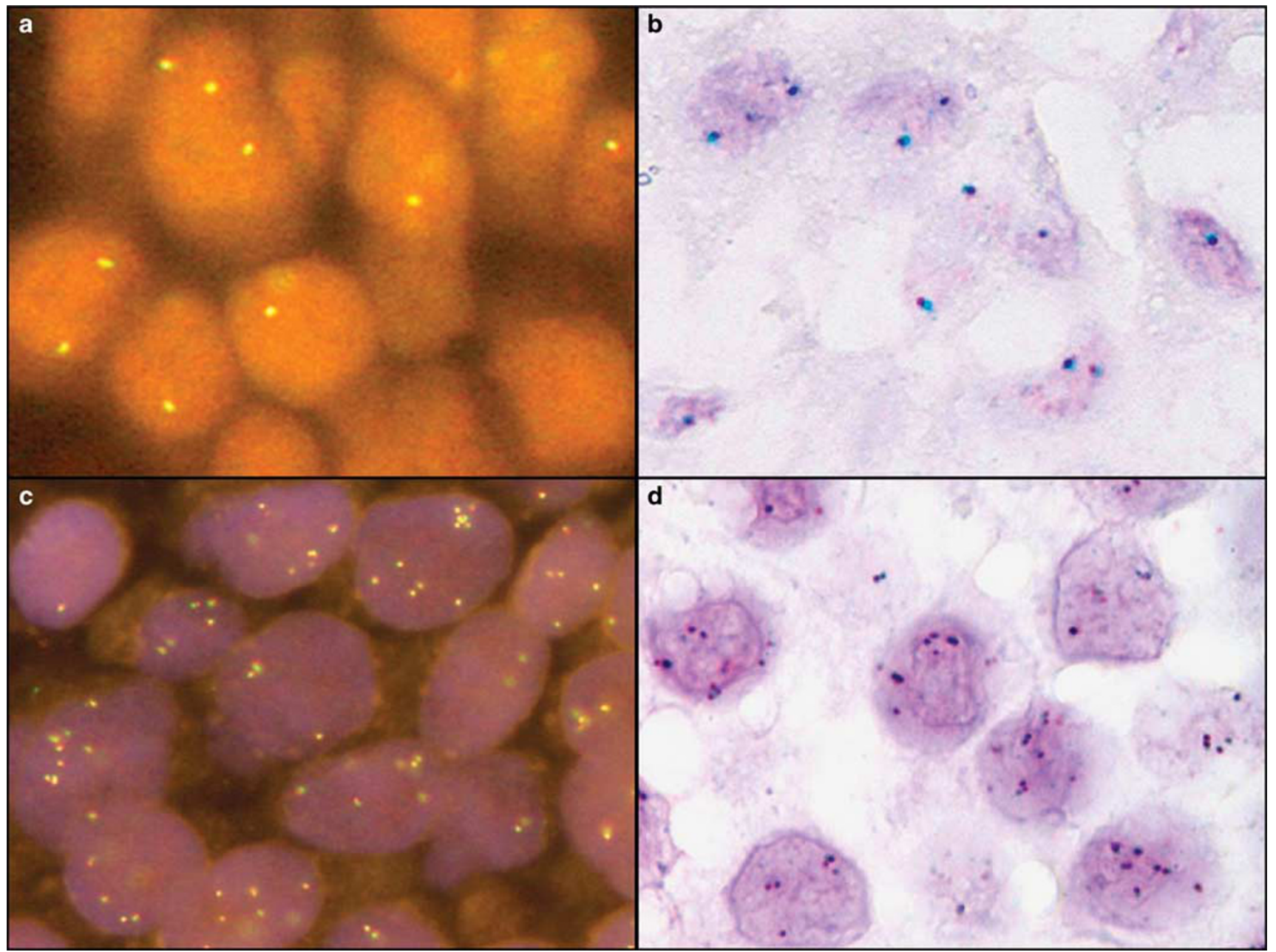

Figure 1 Fluorescent in situ hybridization (FISH) and chromogenic in situ hybridization (CISH) results. FISH (a, c, e, g) and CISH (b, d, f, h) of four pulmonary adenocarcinomas are depicted exemplarily. The first case (a, b) shows one to two fusion signals and is therefore considered negative for $A L K$ (anaplastic lymphoma kinase) rearrangement. In the second case (c, d), a moderate polysomy but no $A L K$ rearrangement was found. In (e, f), an $A L K$-positive pulmonary adenocarcinoma with numerous break-apart signals is shown. Tumor cells in the fourth case $(\mathbf{g}, \mathbf{h})$ harbor many isolated red/orange $3^{\prime}$ signals representing another pattern of $A L K$ rearrangement. CISH and FISH revealed completely concordant signal patterns. 


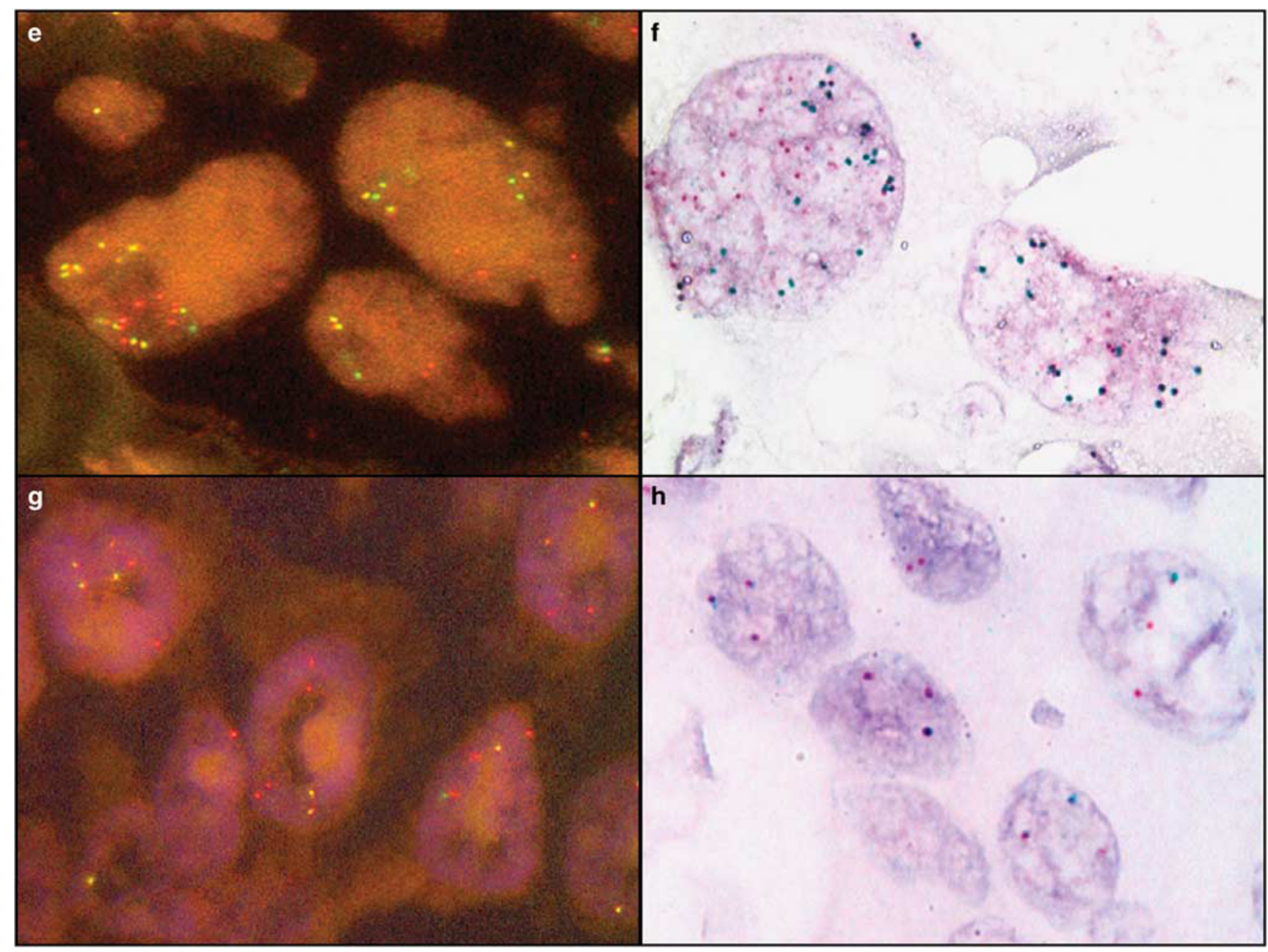

Figure 1 Continued.

often enlarged nuclei, which are frequently truncated by cutting the slides from the paraffin block, some of the signals may be cut off randomly, resulting in 'isolated' red or green signals, which represent artificial parts of former fusion signals. We observed this phenomenon in up to $10 \%$ of nuclei in $A L K$-negative tumors (Table 2). As $A L K$-rearranged tumors may also be polysomic and may reveal a quite similar signal pattern (but with a higher frequency), the distinction between $A L K$-positive and -negative tumors is fundamentally based on the threshold for the percentage of aberrant tumor cells. This approach for the discrimination between truncation artifacts in polysomic tumors and true gene rearrangements is already well established for FISH. In our cohort of $A L K$-negative tumors, we found that this threshold (of $\geq 15 \%$ aberrant tumor cells) is also applicable to our CISH assay because of the aforementioned highly significant correlation between FISH and CISH results.

The minority (about one-third) of $A L K$-rearranged tumors showed a break-apart signal pattern (Figure 1f), which is defined by at least one 'normal' fusion signal and at least one set of split-off red and green signals. We observed that red, green and brownish signals could be well discriminated, with brownish signals being mainly characterized by the dark intensity of color (Figure 1f). This is important for correct evaluation as it is not possible to filter chromogen contents out of the CISH signals with single bandpass filters-as it is for FISH. The distance between red and green signals was mostly larger than two signal diameters; however, break-apart signals with a distance of the size of only one signal were also seen. We have set the threshold at only one signal diameter and considered the latter signal pattern as aberrant. By correlation analysis between FISH and CISH, we found that this threshold level is useful (see above).

Most of the $A L K$-positive tumors were characterized by isolated red $3^{\prime}$ signals beside normal fusion signals (Figure 1h). These cells were easily recognized as most of them harbored multiple isolated red dots, whereas aberrant nuclei with only one isolated $3^{\prime}$ signal were exceedingly rare. It is, however, worth noting that many $A L K$-positive tumors showed a combination of different signal 


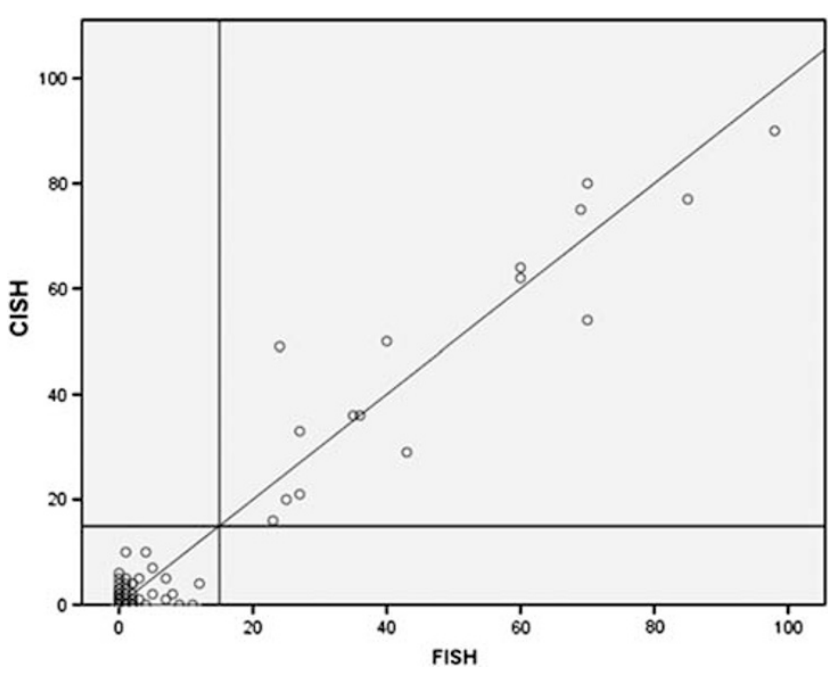

Figure 2 Correlation between $A L K$ (anaplastic lymphoma kinase) chromogenic in situ hybridization (CISH) and fluorescent in situ hybridization (FISH) results. Horizontal and vertical lines indicate the threshold of $15 \%$ aberrant cells. ALK rearranged (top right part of the diagram) and $A L K$-negative cases (bottom left) showed highly significant correlation in terms of the percentages of tumor cells with aberrant signal patterns. False-positive (top left) or false-negative (bottom right) cases were not seen, indicating high sensitivity and specificity of the CISH assay.

Table 2 Pulmonary adenocarcinomas with $7-14 \%$ of aberrant tumor cells in FISH or CISH

\begin{tabular}{lccccc}
\hline Case & $\begin{array}{c}\text { ALK CISH } \\
\text { (percentage } \\
\text { of positive } \\
\text { tumor cells) }\end{array}$ & $\begin{array}{c}\text { ALK FISH } \\
\text { (percentage } \\
\text { of positive } \\
\text { tumor cells) }\end{array}$ & KRAS & EGFR \\
\hline I & $65 / \mathrm{m}$ & 1 & $\mathbf{7}$ & $\mathrm{Wt}$ & $\mathrm{Wt}$ \\
II & $70 / \mathrm{m}$ & 0 & $\mathbf{1 1}$ & $\mathrm{Wt}$ & $\mathrm{Wt}$ \\
III & $80 / \mathrm{m}$ & 2 & $\mathbf{8}$ & $\mathrm{Wt}$ & $\mathrm{Wt}$ \\
IV & $74 / \mathrm{m}$ & 0 & $\mathbf{9}$ & $\mathrm{Wt}$ & $\mathrm{Wt}$ \\
V & $66 / \mathrm{m}$ & Not interpretable & $\mathbf{1 0}$ & $\mathrm{Wt}$ & $\mathrm{Wt}$ \\
VI & $59 / \mathrm{f}$ & 4 & $\mathbf{1 2}$ & $\mathrm{Mut}$ & $\mathrm{ND}$ \\
VII & $64 / \mathrm{m}$ & 5 & $\mathbf{7}$ & $\mathrm{Wt}$ & $\mathrm{Wt}$ \\
VIII & $69 / \mathrm{m}$ & $\mathbf{1 0}$ & 1 & $\mathrm{Mut}$ & $\mathrm{Wt}$ \\
IX & $80 / \mathrm{f}$ & $\mathbf{1 0}$ & 4 & $\mathrm{Wt}$ & $\mathrm{Wt}$ \\
X & $56 / \mathrm{f}$ & $\mathbf{7}$ & 5 & $\mathrm{Wt}$ & $\mathrm{Wt}$ \\
\hline
\end{tabular}

m, male; f, female; wt, wild type; mut, mutated; ND, not determined. Bold numbers indicate percentage of tumor cells with aberrant signal patterns in the range of $7-14 \%$.

patterns in adjacent tumor cells, for example, multiple fusion signals in some nuclei and isolated red signals or even break-apart signals in another part of lesional cells. Furthermore, combinations of aberrant signal patterns within the same tumor cells were found, for example, a combination of fusion signals, multiple isolated red signals and only one or few green signals, or a combination of two red and one green signal. These complex patterns can only hardly be attributed to either 'break-apart' or 'isolated $3^{\prime}$ signals', but have to be regarded and counted as aberrant.

\section{EML4 CISH}

Exemplarily, three tumors were examined using the EML4 break-apart dual-color CISH assay, one ALKnegative, one $E M L 4-A L K$ inversion-positive and one non-EML4 rearranged $A L K$-positive tumor (ie, a carcinoma in which an $A L K$ translocation occurred, but with another translocation partner instead of EML4). All cases showed clear distinct red and green or fusion signals and were easily evaluable. Using the same evaluation criteria as for $A L K$ (evaluation of 100 tumor cells, cutoff level $\geq 15 \%$ ), the EML4 results were in complete concordance.

In the $A L K$-negative tumor, no EML4 break-apart signals were found in any of the 100 evaluated tumor nuclei. ALK CISH of the same lesion showed $6 \%$ of tumor cells with an $A L K$ break-apart signal. The EML4-ALK-positive tumor revealed EML4 breakapart signals in $80 \%$ of the nuclei ( $A L K$ CISH: $90 \%$ break apart). Finally, the non-EML4 ALK-rearranged tumor showed EML4 break-apart signals in only 5\% of the nuclei (EML4-negative), whereas 16\% of tumor cells revealed aberrant signal patterns in the $A L K$ CISH (ALK FISH: 23\%; ALK positive). These results were further proven by subsequent hybridizations with the TriCheck EML4-ALK FISH probe set (ZytoVision), which allows combined and synchronous evaluation of both $A L K$ and EML4 gene rearrangements in the same tumor cells and by one single hybridization (not shown).

\section{Discussion}

Lung cancer is the leading cause of cancer-related deaths worldwide. ${ }^{30}$ It has a poor 5 -year survival as it is often diagnosed in late stages. ${ }^{31} A L K$ rearrangements define a molecular subtype of pulmonary carcinomas and have high clinical relevance because the tyrosine kinase inhibitor crizotinib was recently approved by FDA and EMA because of its superiority to conventional chemotherapy and other targeted drugs in $A L K$ positive carcinomas. Therefore, there is an urgent clinical need for fast and reliable $A L K$ tests.

Currently, FISH is regarded as the gold standard in the diagnosis of $A L K$ gene rearrangements. However, it has several disadvantages including the need of a fluorescence microscope for interpretation. Furthermore, the fluorescent signals fade rapidly and it is difficult to detect overall morphology and tumor heterogeneity. ${ }^{18,26}$ CISH overcomes some of the disadvantages of FISH, for example, a standard light microscope is sufficient for the evaluation of signals $^{32}$ and the slides can be archived for long term. ${ }^{26}$ Finally, compared with FISH, total costs for equipment and consumables are lower.

A disadvantage of common CISH assays is the fact that the signals might be difficult to evaluate with regard to their color appearance. It might sometimes be hard or even impossible to decide whether a 
given signal consists of both colors or not because single bandpass filters cannot be used (in contrast to FISH). Furthermore, bubbles in the mounting medium can compromise the signal evaluability.

Having evaluated a well-characterized cohort of pulmonary adenocarcinomas with known $A L K$ status, we could demonstrate that this newly developed CISH assay can overcome these issues. We saw clearcut dark red and dark green signals and were able to discriminate them easily from fusion signals, which appeared dark brownish or less frequently as overlapping red and green signals. This is a major advantage of this CISH assay as $A L K$ rearrangements in pulmonary carcinomas belong to the most complex genetic changes, which have ever become diagnostically relevant.

These changes include 'classical' reciprocal translocations between $A L K$ on chromosome $2 \mathrm{p}$ and various translocation partners from other chromosomes (eg, KIF5B, TFG). These particular alterations result in a predominating break-apart pattern in the CISH, which is characterized by the simultaneous occurrence of fusion as well as numerically balanced isolated red and green signals. More often, however, an interstitial intrachromosomal inversion occurs on chromosome $2 \mathrm{p}$, which leads to the formation of an ALK-EML4 fusion gene. This subtype of rearrangement may also result in break-apart patterns. However, as the genetic distance between both genes is only $13 \mathrm{Mb}$, the gap between the red probe signal (flanking the $A L K$ gene telomerically at the $3^{\prime}$ end, which contains the pathogenetically relevant tyrosine kinase domain) and the green signal (spanning the $A L K$ gene centromerically to the break point) can be small. Therefore, we set the threshold for the minimal distance between red and green signals to be regarded as break apart to one signal diameter. This break-apart pattern occurred, however, only in about one-third of $A L K$-rearranged tumors from our series. More frequently, complex rearrangements were found, which are characterized by an additional deletion of $5^{\prime}$ parts of the $A L K$ gene. This phenomenon results in the loss of green signals and the appearance of isolated red signals. Moreover, we have observed that rearranged alleles are frequently amplified, resulting in multiple isolated red $3^{\prime}$ signals or break apart signals. Furthermore, the $A L K$ assay gains complexity (i) by frequent polysomy of tumors, (ii) by truncation artifacts, which are the result of cutting CISH slides from paraffin blocks, and (iii) by the fact that various aberrant signal patterns might occur simultaneously. In our study, we could demonstrate that this dual-color CISH assay is suitable for the correct evaluation of such various and complex genetic rearrangements.

We evaluated a series of 100 pulmonary adenocarcinomas, including 17 cases with proven $A L K$ rearrangement by CISH. The frequency of $A L K-$ positive lung cancers is $4.1 \%$ in our diagnostic routine. For this validation study, however, we wanted to include four times more positive cases to allow an evaluation of pattern variability and to increase the statistical power of our validation study. Thus, based on 86 evaluable cases, we were able to demonstrate that this CISH assay has a 100\% sensitivity and $100 \%$ specificity compared with the only hitherto FDA-approved detection method, that is, the Abbott FISH test. We provide evidence that the ZytoVision CISH assay is a reliable test for correct classification of pulmonary adenocarcinomas as $A L K$ positive or negative. Furthermore, we observed a highly significant correlation between FISH and CISH with regard to the percentages of aberrant tumor cells in both $A L K$-positive and negative carcinomas. In addition, we found that the frequency of diagnostically challenging negative cases with increased percentages of aberrant cells (borderline negative tumors with up to $14 \%$ of aberrant cells) is lower (3.5\% CISH vs 7\% FISH). However, a disadvantage of the CISH assay in our study was an increased rate of cases, which were not interpretable either because of overdigestion, washed off tissue or to bad signal quality (CISH $12 \%$ vs FISH 1\%). This might, however, at least partially be attributable to the fact that we as a reference institute used paraffin blocks with tissues from different laboratories with various fixation protocols. Therefore, we expect that the CISH failure rate could decrease after additional steps of protocol optimization as we experienced after starting $A L K$ FISH a couple of years ago.

To the best of our knowledge, this is the first report using and validating a commercially available dualcolor CISH test for the detection of $A L K$ rearrangements in pulmonary carcinomas. We are convinced that this assay is also useful for the diagnosis of $A L K$ rearrangements in anaplastic large-cell lymphomas and in inflammatory myofibroblastic tumors.

On the basis of our experience with this $A L K \mathrm{CISH}$ assay, we recommend the following evaluation and reading strategy:

(1) It is useful to include positive and negative controls in each run. These controls might also serve as reference for the color appearance of red and green and brownish fusion signals.

(2) Use a $\times 100$ objective with oil immersion and maximum brightness of the microscope.

(3) Exclude tissue areas with signs of overdigestion and poor preservation from evaluation.

(4) Evaluate 100 non-overlapping nuclei from at least two areas.

(5) Count the number of aberrant tumor cell nuclei, which are defined by (i) break-apart signal pattern (at least on fusion signal plus at least one set of split-off red and green signals with a distance of at least one signal diameter), (ii) isolated 3 '-signal pattern (at least one fusion signal plus one or multiple isolated red signals) or (iii) a combination of both patterns (occurring either in different tumor cells or as complex pattern within the same tumor cell). 
(6) Consider tumors as positive for $A L K$ rearrangement if at least $15 \%$ of lesional cells harbor aberrant signal patterns.

In a recent in vitro study by Heuckmann et al, ${ }^{33}$ different $A L K$ fusion genes and EML4-ALK variants were shown to exhibit different sensitivity to the ALK kinase inhibitors crizotinib and TAE684. FISH and CISH assays allow only the detection of the presence of $A L K$ rearrangement but cannot identify the particular $A L K$ translocation partner. Therefore, it might be useful to add the EML4 CISH test in certain cases. However, future studies are needed to clarify whether these additional tests might become clinically relevant.

\section{Acknowledgements}

We appreciate the expert technical assistance of Theresa Buhl, Ellen Paggen, Claudia Dorloff, Anna Sotnikov, Susann Zupp, Katharina Weckermann and Julia Schumann. This work was supported by the Lung Cancer Group Cologne (LCGC).

\section{Disclosure/conflict of interest}

HUS has received honoraria and reimbursements from Pfizer, Abbott Molecular and Roche Pharma, and grants, honoraria and reimbursements from Novartis Oncology. MM is an employee of ZytoVision. SH is a managing shareholder of ZytoVision. SMB received honoraria from Novartis Oncology, and grants, honoraria and reimbursements from Roche Pharma.

\section{References}

1 Kwak EL, Bang YJ, Camidge DR, et al. Anaplastic lymphoma kinase inhibition in non-small-cell lung cancer. N Engl J Med 2010;363:1693-1703.

2 Soda M, Choi YL, Enomoto M, et al. Identification of the transforming EML4-ALK fusion gene in non-smallcell lung cancer. Nature 2007;448:561-566.

3 Koivunen JP, Mermel C, Zejnullahu K, et al. EML4ALK fusion gene and efficacy of an ALK kinase inhibitor in lung cancer. Clin Cancer Res 2008;14: 4275-4283.

4 Morris SW, Kirstein MN, Valentine MB, et al. Fusion of a kinase gene, ALK, to a nucleolar protein gene, NPM, in non-Hodgkin's lymphoma. Science 1994;263: 1281-1284.

5 Stoica GE, Kuo A, Aigner A, et al. Identification of anaplastic lymphoma kinase as a receptor for the growth factor pleiotrophin. J Biol Chem 2001;276: 16772-16779.

6 Stoica GE, Kuo A, Powers C, et al. Midkine binds to anaplastic lymphoma kinase (ALK) and acts as a growth factor for different cell types. J Biol Chem 2002;277:35990-35998.

7 Lamant L, Dastugue N, Pulford K, et al. A new fusion gene TPM3-ALK in anaplastic large cell lymphoma created by a (1;2)(q25;p23) translocation. Blood 1999;93:3088-3095.

8 Lawrence B, Perez-Atayde A, Hibbard MK, et al. TPM3-ALK and TPM4-ALK oncogenes in inflammatory myofibroblastic tumors. Am J Pathol 2000;157: 377-384.

9 Debelenko LV, Raimondi SC, Daw N, et al. Renal cell carcinoma with novel VCL-ALK fusion: new representative of ALK-associated tumor spectrum. Mod Pathol 2011;24:430-442.

10 Takeuchi K, Choi YL, Togashi Y, et al. KIF5B-ALK, a novel fusion oncokinase identified by an immunohistochemistry-based diagnostic system for ALK-positive lung cancer. Clin Cancer Res 2009;15:3143-3149.

11 Rikova K, Guo A, Zeng Q, et al. Global survey of phosphotyrosine signaling identifies oncogenic kinases in lung cancer. Cell 2007;131:1190-1203.

12 Duyster J, Bai RY, Morris SW. Translocations involving anaplastic lymphoma kinase (ALK). Oncogene 2001;20:5623-5637.

13 Peters S, Adjei AA, Gridelli C, et al. Metastatic non-small-cell lung cancer (NSCLC): ESMO Clinical Practice Guidelines for diagnosis, treatment and follow-up. Ann Oncol 2012;23(Suppl 7):vii56-vii64.

14 NCCN Clinical Practice Guidelines in Oncology: nonsmall cell lung cancer: version 2.2013. National Comprehensive Cancer Network website. www.nccn. org (published 2013).

15 Thunnissen E, Bubendorf L, Dietel M, et al. EML4-ALK testing in non-small cell carcinomas of the lung: a review with recommendations. Virch Arch 2012;461:245-257.

16 Mino-Kenudson M, Chirieac LR, Law K, et al. A novel, highly sensitive antibody allows for the routine detection of ALK-rearranged lung adenocarcinomas by standard immunohistochemistry. Clin Cancer Res 2010;16:1561-1571.

17 Takeuchi K, Choi YL, Soda M, et al. Multiplex reverse transcription-PCR screening for EML4-ALK fusion transcripts. Clin Cancer Res 2008;14:6618-6624.

18 Yoo SB, Lee HJ, Park JO, et al. Reliability of chromogenic in situ hybridization for epidermal growth factor receptor gene copy number detection in non-small-cell lung carcinomas: a comparison with fluorescence in situ hybridization study. Lung Cancer 2010;67:301-305.

19 Rodig SJ, Mino-Kenudson M, Dacic S, et al. Unique clinicopathologic features characterize ALKrearranged lung adenocarcinoma in the western population. Clin Cancer Res 2009;15:5216-5223.

20 Paik JH, Choe G, Kim H, et al. Screening of anaplastic lymphoma kinase rearrangement by immunohistochemistry in non-small cell lung cancer: correlation with fluorescence in situ hybridization. J Thorac Oncol 2011;6:466-472.

21 Shaw AT, Yeap BY, Mino-Kenudson M, et al. Clinical features and outcome of patients with non-small-cell lung cancer who harbor EML4-ALK. J Clin Oncol 2009;27:4247-4253.

22 Garcia-Caballero T, Grabau D, Green AR, et al. Determination of HER2 amplification in primary breast cancer using dual-colour chromogenic in situ hybridization is comparable to fluorescence in situ hybridization: a European multicentre study involving 168 specimens. Histopathology 2010;56:472-480.

23 Sholl LM, John Iafrate A, Chou YP, et al. Validation of chromogenic in situ hybridization for detection of 
EGFR copy number amplification in nonsmall cell lung carcinoma. Mod Pathol 2007;20:1028-1035.

24 Schiavon BN, Jasani B, de Brot L, et al. Evaluation of reliability of FISH versus brightfield dual-probe in situ hybridization (BDISH) for frontline assessment of HER2 status in breast cancer samples in a community setting: influence of poor tissue preservation. Am J Surg Pathol 2012;36:1489-1496.

25 Yoshida A, Tsuta K, Nitta H, et al. Bright-field dualcolor chromogenic in situ hybridization for diagnosing echinoderm microtubule-associated protein-like 4-anaplastic lymphoma kinase-positive lung adenocarcinomas. J Thorac Oncol 2011;6:1677-1686.

26 Kim H, Yoo SB, Choe JY, et al. Detection of ALK gene rearrangement in non-small cell lung cancer: a comparison of fluorescence in situ hybridization and chromogenic in situ hybridization with correlation of ALK protein expression. J Thorac Oncol 2011;6:1359-1366.

27 Travis WD, Brambilla E, Noguchi M, et al. International association for the study of lung cancer/american thoracic society/european respiratory society international multidisciplinary classification of lung adenocarcinoma. J Thorac Oncol 2011;6:244-285.
28 Travis WD, Brambilla E, Muller-Hermelink HK, Harris CC(eds) World Health Organization Classification of Tumours. Pathology and Genetics of Tumours of the Lung, Pleura, Thymus and Heart. IARC Press: Lyon, 2004;26p.

29 Ney JT, Froehner S, Roesler A, et al. High-resolution melting analysis as a sensitive prescreening diagnostic tool to detect KRAS, BRAF, PIK3CA, and AKT1 mutations in formalin-fixed, paraffinembedded tissues. Arch Pathol Lab Med 2012;136: 983-992.

30 Herbst RS, Heymach JV, Lippman SM. Lung cancer. N Engl J Med 2008;359:1367-1380.

31 Son JW. Year-in-review of lung cancer. Tuberc Respir Dis (Seoul) 2012;73:137-142.

32 Nitta H, Zhang W, Kelly BD, et al. Automated brightfield break-apart in situ hybridization (ba-ISH) application: ALK and MALT1 genes as models. Methods 2010;52:352-358.

33 Heuckmann JM, Balke-Want H, Malchers F, et al. Differential protein stability and ALK inhibitor sensitivity of EML4-ALK fusion variants. Clin Cancer Res 2012;18:4682-4690. 